\title{
The Use of Electronic Educational Resources and Innovative Educational Technologies in University Education
}

\author{
https://doi.org/10.3991/ijet.v15i16.14909 \\ Inga Maslova $\left({ }^{\varpi}\right)$, Gulnara Burdina, Irina Krapotkina \\ Elabuga Institute (branch) of Kazan (Volga Region) Federal University, \\ Elabuga, Russian Federation \\ imaslovainga@gmail.com
}

\begin{abstract}
The penetration of digital technologies in the field of human sciences requires the use of more diverse teaching methods and techniques. Electronic educational resources (EER), which include a whole range of educational materials, allow varying the forms of teaching and contribute to improving the quality of education. This study analyses international experience in the development and implementation of EER and offers a practical description for organizing electronic teacher education with the bachelor's degree programmes. We tried to consider the specificity of using e-learning in the field of human sciences, specifically history. The study describes original development of electronic educational resources that have effectively proven themselves when working with students: the Eureka forum, creating a database project, text analysis of academic articles and creating a digest of scientific research on the problem. The study offers e-learning techniques that allow in a digital environment to preserve the traditional learning model - lecture-andbook model. To determine the impact of the e-learning, we conducted a survey among 98 students to evaluate the degree of involvement in the e-learning process and to obtain an assessment of its use in teaching practice. The study results can be practically used for creating new electronic educational resources focusing on distance education.
\end{abstract}

Keywords-Active learning, e-learning, e-learning resources, educational process design, reading literacy.

\section{Introduction}

The transition of all forms of intellectual potential to digital, in particular, the process of digitizing printed materials, including scientific works, educational and methodological materials, periodicals and much more, becomes the most important incentive to change the format of higher education [1,2]. An appropriate level of information service is required to ensure this format, i.e. opportunities to access sources of verified information [3]. 
Many researchers emphasize that e-education has several levels of systemic implementation that require solving problems at several organizational levels $[1,4]$. According to some researchers, the easiest way to electronize learning is to transfer part of the training material, training tasks and additional materials to the cloud-based services available on mobile platforms or to the university servers. Such an approach makes it possible to simplify the work of the teacher, extend the learning time for students due to extracurricular time, and implement the "Anytime Anywhere Learning" concept important for the 21 st century skills [5,6]. Lau et al. [7] indicate that originally most training manuals in many specialties contained a significant part of media content (educational audio, video, photo materials, electronic versions of texts and textbooks, sets of exercises in electronic recordings that duplicated the printed version). Now, due to widespread use and penetration of e-learning, more and more textbooks are created exclusively in digital format and are available on the Internet, which eliminates the need for their printing, reduces the cost of publication and preparation, and also eliminates the lag in the knowledge rate of change. The main problem of the higher education for a while was that during the preparation of the printed edition of the textbook, the information contained in it became irrelevant $[4,7]$.

The value of electronic resources is growing sharply in the context of the process of constant updating of federal state educational standards of higher education in the Russian Federation (RF) (for the period from 2009 to 2018, Federal Educational Standard of Pedagogical Education was accepted for the fourth time) [8], in which less and less time is allocated to contact (classroom) work with students, while the amount of knowledge and abilities necessary for mastering the educational program is increasing. This process requires innovative forms of bringing educational material to the student and monitoring the quality of education. The use of EER in the learning process of students could be one of the solutions.

The Russian Federal Educational Standard of Pedagogical Education 44.03.05 (with two training profiles) determines the need to ensure access for students to the digital learning environment of the university. The standard defines that it includes: "The digital learning environment of the organization should provide: access to curricula, work programs, electronic educational publications and electronic educational resources specified in the work programs of disciplines" (FES PE). Thus, in addition to the educational and methodological materials of the university, the digital learning environment includes access to open network resources, electronic libraries, working with which requires special skills in the selection and systematization of scientifically reliable information. This approach complies with the generally accepted world standard for teaching, which is based on copyrighted programs supported by teachers or groups of teachers, both privately and based on established state educational programs [9-11].

The role of electronic educational resources is particularly high for the human sciences. The STEM training is increasingly being used in the field of technical and physical-mathematical, engineering and natural sciences, as it involves practical activities based on the knowledge gained. This teaching methodology involves the prevalence of full-time (face-to-face) and classroom teaching. Therefore, the role of e- 
learning and distance learning in this area is still a point of active scientific discussion [12]. Meanwhile, a critical factor for the human sciences is access to the widest area of resources and the connection between them (links to sources, the quick accessibility of the transition from one source to another, etc.) [13]. E-learning is the most effective mainly for the human sciences teaching, and it is especially emphasized by research from the Far East, with an older writing and cultural tradition, which requires a more complex structure for training specialists $[13,14]$.

The article provides an analysis of personal experience in the development and implementation of EER for education teacher training programmes (profile History, social studies). The aim of the study is to demonstrate the importance of the EER use in the teaching human sciences and to provide students assessment on the need to use electronic education resources.

\section{Materials and Methods}

The copyright electronic educational resources of Kazan Federal University are placed in the Moodle system. Students, having registered in their personal accounts, have the opportunity to sign up for a specific electronic educational course, while gaining access to electronic lectures and materials of practical classes, on-line or offline consultations, the possibility of obtaining additional points for passing tests, completing tasks and scientific research projects.

The process of preparation and compilation of EER is regulated both by federal and university standards. According to GOST R 53620-2009 "Information and Communication Technologies in Education. Electronic Learning Resource. General Regulations.", electronic educational resources is an educational resource in electronic digital form that includes the structure, subject content and metadata about them [15]. Mandatory availability of metadata, including information about the author, a complete description of the EER (annotation, keywords, target audience, etc.) seriously increases the author's responsibility for the accuracy of the information presented in the educational resource.

An undoubted positive quality of such an EER is its "linkage" to a specific educational program and even an implemented discipline. This opens up the possibility for a student to consciously independently successfully assimilate scientific knowledge within educational program, the formation of skills and competencies, including assimilation, that is, the "ability to learn". Meanwhile, there is the possibility of applying the acquired knowledge and skills in classroom.

The complex EER are of the greatest value due to nature, types and formats of the material presented in the electronic resource. Additionally, besides the curriculum, the electronic course of lectures and practical exercises, materials for controlling knowledge and testing skills, the complex EER includes a set of tasks for the teacher and student to work together (forums for communication, discussion by students and teachers of issues on the course or news forum) 


\subsection{The structure and functions of EER}

Communication in the news forum involves introducing students to the rules of working with EER in the current academic year, with innovations and changes in the sections of the course, e.g. changing the timing of tasks, the appearance of new publications in the list of sources and literature.

Students get access to forums for communication and discussion by students and teachers on the course matter. Problem-based learning (PBL) is applied here. The problem-based learning helps to activate the thought process by the student analysing the actual historical material and operating on it so as to independently obtain new information from it, to come to their own conclusions. A student needs a new application of already known knowledge, shows creative thinking, which solves the serious problem of perceiving ready-made conclusions (based on "Eureka" forum). The discussion on the forum is open so that students can see each other's answers and have the opportunity to comment and have a constructive discussion. Tasks on the ability to formulate questions of different cognitive types are proposed: a clarifying question; practical question; assessment question; question-interpretation, creative question. The opportunity for students to independently create a forum on the course and develop working methods is one of the options for working with the forum.

Thus, the answer to the question of the forum: "Why did the King of Francs Karl go down in history as the Great?" Give five arguments,"- not only develops critical thinking of students, but also leads them to an active scientific analysis of sources, educational and scientific literature, in order to argue their point of view. The openness of the discussion is an undoubted advantage of the forum. Students, seeing the answers of their fellow students, firstly, try not to repeat what has already been said, secondly, they can comment on them, supplementing or refuting the expressed point of view.

The same forum helps to get certain skills, for example, correctly develop various types of questions to a specific topic. A well-developed question suggests the possibility of alternative answers. Meanwhile, the student has to analyse information from the perspective of logic and apply the results to non-standard situations. For instance, while studying "England in the XIII century", using the EER, there can be created a forum on "Magna Carta", where students can ask five types of questions based on an analysis of this historical document.

The technology of project training can be implemented using the "Database" module. This module allows EER users to create, maintain, and search from a collection of records. Structuring records is set by the teacher through the number of margins.

For example, students are given the task of forming the database "The Middle Ages in the Masterpieces of World Painting". The teacher sets five margins that the student must fill in for creating a "Database" on a given topic: 
- Artist / sculptor

- Name and year of creation of the painting / sculpture

- Description of the painting / sculpture

- Image (in JPG format)

- Information support (list of basic and additional literature, Internet resources on the history of paintings / sculptures).

Margins types include check boxes, switch button, drop-down lists, menus, text areas, hyperlinks, images, and downloads. The auto-linking filter allows you to automatically associate any database record with the same words or phrases encountered in the course. The teacher can allow commenting and supplementing the records of the database.

Filling in gaps, the student works on the project, which contributes to the formation of independence and creativity. Thus, a database on works of art reflects events of medieval history. The technology of project training, in this case, acquires the features of a cultural-historical phenomenon that helps to overthinking the content of education, acquiring new knowledge and activities.

The database can be of many uses for the human sciences, such as:

- Collections of dynastic tables

- Album of creative works (students create coats of arms and heraldic symbols of the Middle Ages; arabesques, etc.)

- Joint collections of web links to books, bibliographic references

- Joint photo collections on given topics ("Monuments of Gothic architecture", "Places of memory of medieval Europe")

The proposed projects can be carried out individually or by a group of students.

For the EER "Museology", students carry out a collective project to create the "Family Artefacts" database, where each student uploads photographs, descriptions, and legends about the relics stored in their families. The result of this collective project was a database, which is an original virtual collection of museum significance objects. Thus, the project has a huge educational potential, as aims to preserve family traditions and values.

The projects created by students are of an interdisciplinary nature, e.g. when studying "Methods of Teaching History," they are asked to draw up methodological development for the project (earlier created by a student when working with EER, as part "History of the middle ages"), indicating all structural elements of the project: hypotheses, goals and objectives, methods and approaches, result. A student can act as bath a participant in the program, and the author of the project methodological development.

The resource of the EER "Analysis of a scientific article" on a specific topic is directed to students for developing reading literacy. The structure of the information supply has changed as textual information has moved to the screens of a computer and a smartphone. Thus, students need to develop new cognitive strategies in focused reading. Therefore, success in semantic reading should no longer be determined 
simply by the ability to read and understand the text. Moreover, working with historical text is a complex thought process, even if read the terms correctly and understand the content of the text, because the text of a historical source is, first of all, a cultural product of a certain chronological period. Under "Analysis of a scientific article", students are offered an academic scientific text and assignments to it, which are aimed at deploying complex information processing strategies, including analysis, synthesis, integration and interpretation. The success of semantic reading also includes the ability to use information from different subject areas, to introduce technologies for the effective search, sorting and filtering of a huge amount of information. The EER "Digest of Scientific Articles" resource is amid on developing of these skills. It is implemented as a collective database creating of the most interesting scientific materials recently printed (in the form of electronic links). Meanwhile, students are invited to write their own annotation and keywords for the proposed topic, and formulate a case study for him.

The element of the EER "Lecture" is implemented using active learning technology. This is a special form of the educational process, in which the student cannot but participate in the cognitive process. The "Lecture" element provides the teacher with lots of opportunities to fill content and use various methods of working on it.

The student is invited to gradually study all sections of the lecture right after getting acquainted with the topic, lecture plan. The teacher independently sets the stages and conditions for the student to study theoretical material. For example, before working on theoretical lecture of "The Dutch Bourgeois Revolution", the student is asked to study the historical map of the same name. Historical events occur both in time and in space. Students need to master the skills of spatial localization of historical events by working with the map in order to understand the course of the historical process. On the proposed map, Students, with the help of the map, can visually point the areas where the events of the Netherlands bourgeois revolution occurred, identify ways of moving troops, and trace the change in the boundaries of the territories covered by the revolution at its individual stages.

The electronic educational resource offers two ways to work with a historical map: analytical and synthetic. The analytical method consists in analysing and parsing of a completed historical map. Students have the opportunity to consider the various elements of the map associated with the semantic correlation. A synthetic (or inductive) way of exploring a map is more creative, as it reproduces the process of creating a historical map. Students are invited to fill in a clean outline map, turning it into a thematic. Depending on the teacher's "passing" strategy, students can go to another page, return to the previous page, or go to a different path. The student will be able to proceed to the next theoretical question only if all types of tasks (tests, analysis of a historical source) are completed for the previous one. This ensures a consistent study of the topic that has elements of consolidating the studied material by tests, solving problem tasks, source analysing, and working with a historical map. Each stage of the lecture is evaluated. 


\subsection{Research design}

The survey involved 98 students of pedagogical department. An educational element "Assignment" was created to each of the implemented EER during preparing the study. It allows adding communicative assignments, collecting student projects, analysing and providing feedback on them. It was presented in this form of the questionnaire: "Pros and cons of using electronic educational resources in the educational process" provided to the students. An analysis of the answers allowed drawing conclusions on practical use of EER in the educational process and the possibilities for improving it.

The questionnaire contained five questions:

1. "Do you use EER in the learning process?" and answer options (underline the answer): "in preparation for the lessons"; "in class"; "for self-education"; "Other" (specify).

2. "What is the frequency of EER use in your case ("daily", "1 time per week", "1 - 2 times a month")?"

3. "What elements of the EER seem to you the most "interesting" (collections of sources (anthologies, workshops); glossaries; dynastic tables; forums; tasks (tests, laboratory work); work with video resources; analysis of scientific articles)?"

4. "What elements of the EER seem to you the most"useful" (collections of sources (anthologies, workshops); glossaries; dynastic tables; forums; tasks (tests, laboratory work); work with video resources; analysis of scientific articles)?"

5. "Rate on a 10-point scale the possibility of replacing classroom studies with distance education. (If you think that in the learning process you need to use only distance learning, put 10 points; if you think that half of the classes should be in the classroom, put 5 points, etc.)."

The questionnaire was created to fully cover all the important aspects of the determining points of e-learning.

\section{$3 \quad$ Results and Discussions}

Hundred percent of the respondents chose "In preparation for classes" in response to the first question. On the one hand, this means that EER is actively used by students in the learning process. On the other hand, it shows a lack of desire to work with resources that include additional course materials aimed at self-education of students.

According to the frequency of EER using, $73 \%$ of respondents indicated that they use electronic course materials once a week, which corresponds to the frequency of seminars (one lesson a week). 5\% of respondents indicated that they access to EER 12 times a month, and $26 \%$ - daily.

The list of most-to-least interesting means provided in the 3rd question was distributed as follows:

- Work with video resources 
- Tasks (tests, laboratory work)

- Analysis of scientific articles

- Collections of sources (anthologies, workshops)

- Texts of lectures

- Dynastic tables; forum

- Glossaries

The response to the fourth question has changed the picture. There were three most frequently used resources: lecture texts (58\%); tasks (tests, laboratory work) $(62 \%)$; work with video resources $(71 \%)$. The second position was taken by collections of sources (anthologies, workshops) (32\%) and analysis of scientific articles (29\%).

Such elements of the course as "Forum", "Dynastic tables", "Glossaries" were at the end of the list same as for the previous question. These elements are aimed at students' self-education, which confirms the lack of interest in it.

The results of the survey showed that students prefer video formats for presenting material that arouse their interest and awareness of the information usefulness. Meanwhile, students recognize the benefits of working with lecture texts and assignments.

In response to the fifth question, $57 \%$ of respondents gave 5 points, thus they considered that classroom and distance learning should be used in the educational process in the ratio of $50 \%$ to $50 \%$. $26 \%$ of students point out that classroom work should prevail. The remaining $17 \%$ preferred distance learning.

An analysis of the questionnaire generally showed that electronic educational resources are actively used by students in preparation for classes, allow combining the practical and motivational aspects of training, and also form the ability to use ICT technologies in future professional teaching activities.

E-learning today is becoming the de facto standard in higher education, almost all programs have an electronic element, and there are more and more courses created for only online learning. The opportunity of Massive Online Open Courses (MOOC) is also being used more and more widely, which open up the possibility of higher education for anyone who wants to take a chosen course or specialty $[7,16]$.

The widespread use of online learning has led to a deepening towards individualized learning. Researchers point out that even a printed textbook has the feature that develops 1) a certain independence and autonomy of the student from the teacher, 2) the possibility of learning at a pace, character for an individual. However, the printed textbook has enough flexibility to adapt to the conditions of modern society. The e-books have the advantage as it naturally integrates media content, has variability, and can be quickly adapted to new knowledge or training requirements; does not limit the creativity of the teacher; allows the student to independently integrate new content into the learning process. Moreover, as the research results show, the most optimal is the combination of electronic forms of teaching and educational content of printed materials.

The most pressing issues of e-learning is the development of systems for selecting, ranking and linking training materials in accordance with the personal learning strategies of each student, with access to a very large number of resources on the 
Internet, as well as on the servers of educational institutions [17,18]. There were provided both initial models for selecting information for a particular course and models for flexible adaptation of the material in the learning process and in accordance with how the student's knowledge and needs change [19].

The e-learning effectiveness is determined by the great adaptability of this method for generations of people born in the era of a constant digital environment. According to Bae and Shin [20], e-learning technologies are more satisfying, develop more stable motivation and help many students to graduate as some could not do this in other conditions [21].

Most researchers of e-education in the RF believe that a new theoretical approach to e-learning is necessary, since it compares favourably with traditional learning, involving personal contact. Considering EER as an educational tool, it is noted that it is currently used mainly in addition to the main course, as an auxiliary material or as a form of organization of students' independent work [22].

Yakovleva [23] suggests using a blended learning system that combines elements of traditional and electronic education as a mean of transition from the traditional model to a new one in which the position of the teacher and student changes.

Researchers pay attention to the classification features of EER, the goals of their use in the educational process [24]. The active implementation of the EER in the educational process stimulated teachers to broadcast their experience on the pages of scientific publications, which allows not only to generalize the methodological experience, but also to identify issues that remain beyond the scope of research $[25,26]$. The problem of the communicative component between students and the teacher is a point of lots discussions. The experiments on the introduction of distance technologies in elementary school showed the need for direct communication between the teacher and students [27].

American researchers emphasize that e-learning is distinguished by a wide variety of activities (working in online groups, databases), and students' freedom of action [28]. The advantage of correct e-learning over traditional classroom teaching is proved by many researchers. Janelli [29] notes that "unfortunately, learning theory, educational practice and research work are not often found together and there might be e-learning programs that can even reduce educational outcomes", according to the results of introducing MOOC, developed by the American Museum of Natural History in New York, By the start of the 21st century, more than half of US universities and colleges offered distance learning courses. Thus, with over 100,000 different online courses provided, about a quarter of American students take at least one such each semester [30].

\section{Conclusion}

Despite the accumulated knowledge about the types of EER and how to implement them in the learning process, a number of questions still remain open, in particular: "How, by which techniques does a particular person learn?", "What categories of 
students prefer e-learning?", "How to maintain the traditional lecture-and-book model for Russian culture in the context of digitalization of instruction?"

Many years of experience, using integrated electronic educational resources in the educational process, allows us to conclude that the EER gives the university teacher the opportunity to use innovative teaching methods, make individual courses and increase the computerization of education in teaching human science, while retaining semantic competencies reading, reading habits and the ability to analyse textual material. The EER makes it possible to build an individual educational trajectory for each student, introduce the principles of a system-activity approach into the educational process, and increase the independent component of the educational process for students. An analysis of teaching experience, in introducing effective practices of EER for teaching human science at a university even at the micro level (one or two training courses), allows obtaining data that can further improve the design of training courses, and therefore improve the quality of students' training.

The study shows a number of problems in the design of e-learning programs mainly in the lack of sufficient motivation for self-learning and self-processing of the material outside the necessary and sufficient material. Students are also more attracted to media content, while text content is considered as the most useful. Thus, there is a cognitive dissonance among students. Thus, a point of further research should be aimed at determining of methods for e-learning curricula creating that would generate sufficient motivation for independence and provide training content in the form most suitable for qualitative learning. Therefore, the need to form students' cognitive literacy and motivate them to master the course text program is obvious.

\section{$5 \quad$ References}

[1] Alhabeeb, A., Rowley, J. (2018). E-learning critical success factors: Comparing perspectives from academic staff and students. Computers \& Education, 127: 1-12. https:// doi.org/10.1016/i.compedu.2018.08.007

[2] Ferreira, D., Paterson, R., Hakone, K. (2018). The Growth of e-Learning in Higher Education: Preparing an Agenda for a Professional Development Workshop. ICU Language Research Bulletin, 32: 20-31.

[3] Chang, V. (2016). Review and discussion: E-learning for academia and industry. International Journal of Information Management, 36(3): 476-485.

[4] Mesfin, G., Ghinea, G., Grønli, T.M., Hwang, W.Y. (2018). Enhanced Agility of ELearning Adoption in High Schools. Journal of Educational Technology \& Society, 21(4): 157-170.

[5] Anshari, M., Alas, Y., Guan, L.S. (2016). Developing online learning resources: Big data, social networks, and cloud computing to support pervasive knowledge. Education and Information Technologies, 21(6): 1663-1677. https://doi.org/10.1007/s10639-015-9407-3

[6] Kim, K.J., Kim, G. (2019). Development of e-learning in medical education: 10 years' experience of Korean medical schools. Korean Journal of Medical Education, 31(3): 205214. https://doi.org/10.3946/kjme.2019.131

[7] Lau, K.H., Lam, T., Kam, B.H., Nkhoma, M., Richardson, J., Thomas, S. (2018). The role of textbook learning resources in e-learning: A taxonomic study. Computers \& Education, 118: 10-24. https://doi.org/10.1016/j.compedu.2017.11.005 
[8] Ministry of Education and Science of the Russian Federation (2018). Federal State Educational Standards of Higher Education - undergraduate in the direction of preparation 03/03/05 Pedagogical education (with two specialization profiles). Available at: http://fgosvo.ru/uploadfiles/FGOS\%20VO\%203++/Bak/440305_B_3_16032018.pdf (Acce ssed March 11, 2020)

[9] Okeke, A.U., Ihenacho, U. O. (2019). Extent of utilization of e-learning resources in business education programme in south-east Nigerian universities. Nau Journal of Technology and Vocational Education, 2(1): 182-190.

[10] Ramachandran, K., Faith, M. (2020). Design and evaluation of faculty development workshop for teaching, learning and assessment using E-resources in an Indian Medical School. South-East Asian Journal of Medical Education, 13(2): 56-61. https://doi.org/10.40 38/seajme.v13i2.211

[11] Ranieri, M., Raffaghelli, J., Pezzati, F. (2018). Digital resources for faculty development in e-learning: a self-paced approach for professional learning. Italian Journal of Educational Technology, 26(1): 104-118.

[12] Hwang, G.J., Xie, H. (2018). Review and trend analysis of knowledge management and elearning research. Knowledge Management \& E-Learning: An International Journal, 10(4): 371-374. https://doi.org/10.34105/j.kmel.2018.10.022

[13] Shen, W. (2017). Liberal Arts Education and Colleges in East Asia. Educational Studies in Japan, 11: 129-131. https://doi.org/10.7571/esjkyoiku.11.129

[14] Jung, I., Nishimura, M., Sasao, T. (2016). Liberal Arts Education and Colleges in East Asia. Possibilities and Challenges in the Global Age. Singapore: Springer. https://doi.org/ $\underline{10.1007 / 978-981-10-0513-8}$

[15] Moscow State Technological University "Stankin" (2009). GOST R 53620-2009 Information and communication technologies in education. Electronic educational resources. Available at: http://docs.cntd.ru/document/1200082196 (Accessed March 11, 2020)

[16] Ogawa, N. (2018). Active Learning Strategy at a Collegewide Level in NIT, Gifu College. Procedia Computer Science, 126: 1994-2002. https://doi.org/10.1016/j.procs.2018.07.253

[17] Shen, X., Yi, B., Zhang, Z., Shu, J., Liu, H. (2016). Automatic recommendation technology for learning resources with convolutional neural network. In: 2016 International Symposium on Educational Technology (ISET) (pp. 30-34). IEEE. https:// doi.org/10.1109/iset.2016.12

[18] Tarus, J.K., Niu, Z., Mustafa, G. (2018). Knowledge-based recommendation: a review of ontology-based recommender systems for e-learning. Artificial Intelligence Review, 50(1): 21-48. https://doi.org/10.1007/s10462-017-9539-5

[19] Truong, H.M. (2016). Integrating learning styles and adaptive e-learning system: Current developments, problems and opportunities. Computers in Human Behavior, 55: 11851193. https://doi.org/10.1016/j.chb.2015.02.014

[20] Bae, J.H., Shin, H.Y. (2019). A Study on the Factor of Satisfaction or Dissatisfaction of eLearning Using Kano Model and Timko's Customer Satisfaction coefficients. Journal of the Korea Convergence Society, 10(7): 325-333.

[21] Gros, B., García-Peñalvo, F.J. (2016). Future trends in the design strategies and technological affordances of e-learning. Springer.

[22] Kutsenko, S.M., Kosulin, V.V. (2017). Electronic educational resource as a learning tool. Bulletin of Kazan State Energy University, 4(36): 127-133.

[23] Yakovleva, A.G. (2017). The organization of blended learning in the teaching of pedagogical disciplines. Bulletin of Tomsk State Pedagogical University, 4(181): 96-98. https://doi.org/10.23951/1609-624x-2017-4-96-99 
[24] Krasnova, L.A., Shurygin, V.Y. (2019). Blended Learning of Physics in the Context of the Professional Development of Teachers. International Journal of Technology Enhanced Learning, 12(1): 38-52. https://doi.org/10.1504/ijtel.2020.103814

[25] Pervushina, I.I., Kaygorodtseva, N.V. (2012). Didactic and methodological requirements for the development of electronic educational resources. Omsk Scientific Bulletin, 2(110): 292-296.

[26] Skipor, I.L. (2012). Integration of electronic educational resources of a university: development of a unified content structure for the site "Electronic educational environment of KemGUKI". Bulletin of the GUKI, 20: 122-130.

[27] Burdina, G.M., Krapotkina, I.E., Nasyrova, L.G. (2019). Distance Learning in Elementary School Classrooms: An Emerging Framework for Contemporary Practice. International Journal of Instruction, 12(1): 1-16. https://doi.org/10.29333/iji.2019.1211a

[28] Gamble, A. (2017). Developing Data Information Literacy with the Institutional Review Board. In: University of Massachusetts and New England Area Librarian e-Science Symposium.

[29] Janelli, M. (2018). E-learning in theory, practice and research. Educational Studies Moscow, 4: 81-98.

[30] Berg, G.A, Simonson, M. (2016). Distance learning. In: Encyclopedia Britannica. Encyclopædia Britannica Inc. Available at: https://www.britannica.com/topic/distancelearning (Accessed March 11, 2020)

\section{Authors}

Maslova Inga Vladimirovna is a Doctor of Historical Sciences, Professor of the Department of Universal and National History, Elabuga Institute (branch) of Kazan (Volga Region) Federal University, Elabuga, Russian Federation.

Burdina Gulnara Mansurovna is a Candidate of Historical Sciences, Assistant Professor of the Department of Universal and National History, Elabuga Institute (branch) of Kazan (Volga Region) Federal University, Elabuga, Russian Federation.

Krapotkina Irina Evgenievna is a Candidate of Historical Sciences, Assistant Professor of the Department of Universal and National History, Elabuga Institute (branch) of Kazan (Volga Region) Federal University, Elabuga, Russian Federation.

Article submitted 2020-04-16. Resubmitted 2020-05-12. Final acceptance 2020-05-13. Final version published as submitted by the authors. 